Mathematical Modelling and Analysis

Volume 17 Number 4, September 2012, 457-466

http://dx.doi.org/10.3846/13926292.2012.706236

(c) Vilnius Gediminas Technical University, 2012
Publisher: Taylor\&Francis and VGTU

http://www.tandfonline.com/TMMA

Print ISSN: 1392-6292

Online ISSN: 1648-3510

\title{
A Cyclic Algorithm for the Split Common Fixed Point Problem of Demicontractive Mappings in Hilbert Spaces*
}

\author{
Yu-Chao Tang ${ }^{a, b}$, Ji-Gen Peng ${ }^{b}$ and Li-Wei Liu ${ }^{a}$ \\ ${ }^{a}$ NanChang University \\ 330031 Nanchang, China \\ ${ }^{b}$ Xi'an Jiaotong University \\ 710049 Xi'an, China \\ E-mail: hhaaoo1331@yahoo.com.cn
}

Received June 27, 2011; revised April 27, 2012; published online September 1, 2012

\begin{abstract}
The split common fixed point problem has been investigated recently, which is a generalization of the split feasibility problem and of the convex feasibility problem. We construct a cyclic algorithm to approximate a solution of the split common fixed point problem for the demicontractive mappings in a Hilbert space. Our results improve and extend previously discussed related problems and algorithms.
\end{abstract}

Keywords: split feasibility problem, demicontractive mappings, common fixed point.

AMS Subject Classification: 49J53; 65K10.

\section{Introduction}

Let $H$ be a real Hilbert space with inner product $\langle\cdot, \cdot\rangle$ and norm $\|\cdot\|$, respectively. Recall that the convex feasibility problem (CFP) is formulated as follows: If $\bigcap_{i=1}^{n} C_{i} \neq \emptyset$

$$
\text { Find a point } x^{*} \in \bigcap_{i=1}^{n} C_{i},
$$

where $n \geq 1$ is an integer, and each $C_{i}$ is a nonempty closed convex subset of $H$. It has been proved that the convex feasibility problem has great applicability in many areas, such as image reconstruction in computerized tomography,

* This work was supported by the National Natural Science Foundations of China (11131006, 60970149, 11101204, 11102078), the Natural Science Foundations of Jiangxi Province (2009GZS0021, CA201107114) and the Youth Science Funds of The Education Department of Jiangxi Province (GJJ12141). 
radiation therapy treatment planning, electron microscopy and signal processing etc. A complete and exhaustive study on algorithms and applications for solving convex feasibility problem can be found in [1].

The split feasibility problem (SFP, for short) was introduced by Censor and Elfving[4] which is defined as follows:

$$
\text { Find } x \in C \text { such that } A x \in Q \text {, }
$$

where $C$ and $Q$ are nonempty closed convex sets in $\mathbb{R}^{N}$ and $\mathbb{R}^{M}, A$ is an $M \times N$ real matrix.

Let $A^{-1}(Q)=\{x \mid A x \in Q\}$, then the split feasibility problem is equivalent to the convex feasibility problem:

$$
\text { Find } x \in F:=C \cap A^{-1}(Q) \text {. }
$$

So the (SFP) can be viewed as a particular case of (CFP). Censor and Elfving [4] used multidistance method to obtain iterative algorithms for solving the (SFP). Their algorithms involved matrix inverses at each step. Byrne[3] proposed an iterative method called CQ algorithm that involves only the orthogonal projections onto $C$ and $Q$ and does not need to compute the matrix inverse to solve the (SFP). The CQ algorithm is defined as follows:

$$
\left\{\begin{array}{l}
x_{0} \text { be arbitrary, } \\
x_{n+1}=P_{C}\left(x_{n}+\gamma A^{T}\left(P_{Q}-I\right) A x_{n}\right), \quad n \geq 0,
\end{array}\right.
$$

where $\gamma \in\left(0, \frac{2}{L}\right)$ and $L$ denotes the largest eigenvalue of the matrix $A^{T} A$. Later, Yang [18] proposed a relaxed CQ algorithm for solving the (SFP) in which the orthogonal projections $P_{C}$ and $P_{Q}$ are replaced by $P_{C_{n}}$ and $P_{Q_{n}}$, respectively, i.e., the orthogonal projections onto two halfspaces $C_{n}$ and $Q_{n}$, see also $[13,21]$. Both the CQ algorithm and the relaxed CQ algorithm used a fixed stepsize related to the largest eigenvalue of the matrix $A^{T} A$, which sometimes affects convergence of the algorithms. Qu and Xiu [11] developed the CQ algorithm and the relaxed CQ algorithm by adopting Armijo-like searches. In the modified algorithms there is no need to compute the matrix inverses and the largest eigenvalue of the matrix $A^{T} A$, and a sufficient decrease of the objective function is done at each iteration. Some other related results can be found in $[6,9,12,14,15,16,17,19,20]$ and references therein.

The multiple-set split feasibility problem (MSSFP) which finds application in intensity modulated radiation therapy was proposed in [5] and is formulated as:

$$
\text { Find a point } x^{*} \in \bigcap_{i=1}^{N} C_{i} \text {, such that } A x \in \bigcap_{j=1}^{M} Q_{j},
$$

where $N, M \geq 1$ are integers, $\left\{C_{i}\right\}_{i=1}^{N}$ are closed convex subsets of a Hilbert space $H_{1},\left\{Q_{j}\right\}_{j=1}^{M}$ are closed convex subsets of a Hilbert space $H_{2}$ and $A: H_{1} \rightarrow H_{2}$ is a bounded linear operator. If $N=M=1$, then the (MSSFP) reduces to the (SFP). Some projection algorithms for solving the (MSSFP) can be found in $[8,9,16]$. 
The problems (1.2) and (1.4) are all special cases of the so-called split common fixed point problem (SCFP) which is formulated as follow:

$$
\text { Find a point } x^{*} \in \bigcap_{i=1}^{p} F i x\left(U_{i}\right) \text {, such that } A x^{*} \in \bigcap_{j=1}^{r} F i x\left(T_{j}\right) \text {, }
$$

where $p, r \geq 1$ are integers, Fix $(T)$ denotes the fixed point set of $T, A: H_{1} \rightarrow$ $H_{2}$ is a bounded linear operator, $\left\{U_{i}\right\}_{i=1}^{p}: H_{1} \rightarrow H_{1},\left\{T_{j}\right\}_{j=1}^{r}: H_{2} \rightarrow H_{2}$ are nonlinear operators. In particular, if $p=r=1$, then (1.5) reduces to the following

$$
\text { Find a point } x^{*} \in F i x(U) \text {, such that } A x^{*} \in F i x(T) \text {, }
$$

which is usually called the solution set of the two-sets of (SCFP).

Censor and Segal [7] constructed the following algorithms to solve the two sets of (SCFP) for directed operators (the definition is given by Definition 2).

Algorithm. Let $x_{0} \in H_{1}$ be arbitrary, the sequence $\left\{x_{n}\right\}$ defined by:

$$
x_{n+1}=U\left(x_{n}-\gamma A^{*}(I-T) A x_{n}\right), \quad n \geq 0,
$$

where $\gamma \in\left(0, \frac{2}{\lambda}\right)$ with $\lambda$ being the spectral radius of the operator $A^{*} A$. According to this algorithm and using the product space technique, they introduced another algorithm to solve the (SCFP) as follows:

$$
x_{n+1}=x_{n}+\gamma\left[\sum_{i=1}^{p} \alpha_{i}\left(U_{i}\left(x_{n}\right)-x_{n}\right)+\sum_{j=1}^{r} \beta_{j} A^{*}\left(T_{j}-I\right) A x_{n}\right], \quad n \geq 0
$$

where $0<\gamma<\frac{2}{L}$ with $L=\sum_{i=1}^{p} \alpha_{i}+\|A\|^{2} \sum_{j=1}^{r} \beta_{j}$.

Recently, Moudafi [10] proposed an algorithm to solve the solution set of the two-sets of (SCFP) when the operators $U$ and $T$ are demicontractive. The class of demicontractive operators is fundamental because many common types of operators arising in optimization belong to this class (see Remark 2 below). He proved that the sequence $\left\{x_{n}\right\}$ generated by Algorithm 1 converges weakly to the solution of (1.6).

Algorithm 1. [10] Let $x_{0} \in H_{1}$ be arbitrary, the sequence $\left\{x_{n}\right\}$ defined by:

$$
x_{n+1}=\left(1-\alpha_{n}\right) u_{n}+\alpha_{n} U\left(u_{n}\right), \quad n \geq 0,
$$

where $u_{n}=x_{n}+\gamma A^{*}(T-I) A x_{n}, \gamma \in\left(0, \frac{1-\mu}{\lambda}\right)$ with $\lambda$ being the spectral radius of the operator $A^{*} A$ and $\left\{\alpha_{n}\right\} \subset(0,1)$.

Theorem 1. [10] Given a bounded linear operator $A: H_{1} \rightarrow H_{2}$, let $U: H_{1} \rightarrow$ $H_{1}$ and $\mathrm{T}: \mathrm{H}_{2} \rightarrow \mathrm{H}_{2}$ be demicontractive (with constants $\beta$, $\mu$ respectively) with nonempty Fix $(U)$ and Fix $(T)$. Assume that $U-I$ and $T-I$ are demiclosed at 0 . If the two sets of $S C F P(1.6)$ is nonempty, then any sequence $\left\{x_{n}\right\}$ generated by Algorithm 1 converges to a split common fixed point $x^{*}$ of (1.6), provided $\gamma \in\left(0, \frac{1-\mu}{\lambda}\right)$ and $\alpha_{n} \in(\delta, 1-\beta-\delta)$ for a small enough $\delta>0$. 
Inspired and motivated by the above works, we propose a cyclic algorithm to solve the (SCFP). Then we prove that the sequence generated by the proposed algorithm converges weakly to the solution of (SCFP). Our work is extending the results of Moudafi [10], Censor and Segal [7] and others.

Algorithm 2. Let $x_{0} \in H_{1}$ be arbitrary, for $n \geq 0$, calculate

$$
x_{n+1}=\left(1-\alpha_{n}\right) u_{n}+\alpha_{n} U_{i(n)}\left(u_{n}\right), \quad n \geq 0,
$$

where $u_{n}=x_{n}+\gamma A^{*}\left(T_{j(n)}-I\right) A x_{n}, i(n)=n(\bmod p)+1$ and $j(n)=$ $n(\bmod r)+1 . \quad \gamma \in\left(0, \frac{1-\mu}{\lambda}\right)$ with $\lambda$ being the spectral radius of the operator $A^{*} A$ and $\left\{\alpha_{n}\right\} \subset(0,1)$.

Remark 1. Let us consider the particular case $p=r=1$, then our Algorithm 2 reduces to Algorithm 1 proposed by Moudafi [10].

\section{Preliminaries}

In this section, we collect some important definitions and prove some useful lemmas which will be used in the following section. We use the following notations:

(i) $\Omega$ the solution set of $\operatorname{SCFP}(1.5)$.

(ii) $\omega_{w}\left(x_{n}\right)=\left\{x: \exists x_{n_{j}} \rightarrow x\right\}$ denotes the weak $\omega$-limit set of $\left\{x_{n}\right\}$.

(iii) $\rightarrow$ for weak convergence and $\rightarrow$ for strong convergence.

(iv) $\triangle:=\{1,2, \ldots, p\}, \nabla:=\{1,2, \ldots, r\}$.

Definition 1. [10] An operator $T: H \rightarrow H$ is called $k$-demicontractive, if there exists a constant $k \in(0,1)$ such that $\|T x-q\|^{2} \leq\|x-q\|^{2}+k\|x-T x\|^{2}$, for all $x \in H$ and $q \in F i x(T)$.

The following definitions are well known.

Definition 2. Assume that $T: H \rightarrow H$ is an operator with $\operatorname{Fix}(T) \neq \emptyset$,

(i) $T$ is said nonexpansive, if $\|T x-T y\| \leq\|x-y\|$, for all $x, y \in H$.

(ii) $T$ is said quasi-nonexpansive, if $\|T x-q\| \leq\|x-q\|$, for all $x \in H$, $q \in \operatorname{Fix}(T)$.

(iii) $T$ is said strictly pseudocontractive, if

$$
\|T x-T y\|^{2} \leq\|x-y\|^{2}+k\|(I-T) x-(I-T) y\|^{2},
$$

for all $x, y \in H$, and some $k \in(0,1)$.

(iv) $I-T$ is called demiclosed at origin, if for any sequence $\left\{x_{n}\right\} \subset H$ and $x \in H$, we have $x_{n} \rightarrow x$ and $x_{n}-T x_{n} \rightarrow 0$, then $x \in F i x(T)$. 
We recall the definition of directed operator, and one can find its properties in [7] and [2].

Definition 3. [7] $T$ is a directed operator, if

$$
\langle q-T x, x-T x\rangle \leq 0
$$

for all $x \in H$ and $q \in \operatorname{Fix}(T)$.

Two equivalent definition of demicontractive operator is given by the following lemma.

Lemma 1. Let $T: H \rightarrow H$ be $k$-demicontractive operator such that $F i x(T) \neq$ $\emptyset$. Then it is equivalent to the following inequalities:

(i) $\langle x-T x, x-q\rangle \geq \frac{1-k}{2}\|x-T x\|^{2}, q \in F i x(T), x \in H$;

(ii) $\langle x-T x, q-T x\rangle \leq \frac{1+k}{2}\|x-T x\|^{2}, q \in F i x(T), x \in H$.

Proof. (i) Since $T$ is $k$-demicontractive, then there exists a constant $k \in[0,1)$ such that

$$
\|T x-q\|^{2} \leq\|x-q\|^{2}+k\|x-T x\|^{2}, \quad q \in F i x(T), x \in H .
$$

Then

$$
\begin{aligned}
\langle x-T x, x-q\rangle & =\langle x-q+q-T x, x-q\rangle=\|x-q\|^{2}+\langle q-T x, x-q\rangle \\
& \geq\|T x-q\|^{2}-k\|x-T x\|^{2}+\langle q-T x, x-q\rangle \\
& =\langle T x-q, T x-x\rangle-k\|x-T x\|^{2} \\
& =\langle T x-x+x-q, T x-x\rangle-k\|x-T x\|^{2} \\
& =(1-k)\|x-T x\|^{2}-\langle x-q, x-T x\rangle,
\end{aligned}
$$

which implies that

$$
\langle x-T x, x-q\rangle \geq \frac{1-k}{2}\|x-T x\|^{2} .
$$

(ii) By the following

$$
\begin{aligned}
\langle x-T x, q-T x\rangle & =\langle x-q+q-T x, q-T x\rangle=\langle x-q, q-T x\rangle+\|T x-q\|^{2} \\
& \leq\langle x-q, q-T x\rangle+\|x-q\|^{2}+k\|x-T x\|^{2} \\
& =\langle x-q, x-T x\rangle+k\|x-T x\|^{2} \\
& =\langle x-T x+T x-q, x-T x\rangle+k\|x-T x\|^{2} \\
& =\|x-T x\|^{2}-\langle x-T x, q-T x\rangle+k\|x-T x\|^{2},
\end{aligned}
$$

which leads to

$$
\langle x-T x, q-T x\rangle \leq \frac{1+k}{2}\|x-T x\|^{2} .
$$

If either inequality (i) or inequality (ii) holds, then $T$ must be $k$-demicontractive. The proof is just inverse proof of above. So it is omitted. This completes the proof. 
Remark 2. It is easy to see that the demicontractive maps contain the quasinonexpansive maps and the strictly pseudocontractive maps with fixed points. From Lemma 1(ii), we can conclude that a directed operator must be demicontractive.

The following lemma appears implicitly in [10].

Lemma 2. [10] Let $T$ be a k-demicontractive self mapping on $H$ with $F i x(T) \neq$ $\emptyset$ and set $T_{\alpha}:=(1-\alpha) I+\alpha T$, for $\alpha \in(0,1]$. Then, $T_{\alpha}$ is quasi-nonexpansive provided that $\alpha \in[0,1-k]$ and

$$
\left\|T_{\alpha} x-q\right\|^{2} \leq\|x-q\|^{2}-\alpha(1-k-\alpha)\|T x-x\|^{2}, \quad x \in H, \quad q \in \operatorname{Fix}(T) .
$$

Remark 3. It is easy to check that Fix $(T)=$ Fix $\left(T_{\alpha}\right)$. Hence, Fix $(T)$ is a closed convex subset of $H$, as the fixed point set of a quasi-nonexpansive mapping.

Definition 4 . Let $C$ be a nonempty closed convex subset of $H$ and $\left\{x_{n}\right\}$ is a sequence in $H$. The sequence $\left\{x_{n}\right\}$ is called Féjer-monotone with respect to $C$, if $\left\|x_{n+1}-z\right\| \leq\left\|x_{n}-z\right\|, n \geq 0, z \in C$.

Lemma 3. [1] If a sequence $\left\{x_{n}\right\}$ is Féjer-monotone respect to a closed subset of $C$, then $x_{n} \rightarrow x^{*} \in C$ if and only if $\omega_{w}\left(x_{n}\right) \subset C$.

\section{Main Results}

In this section, we consider a finite family of demicontractive mappings of $\left\{U_{i}\right\}_{i=1}^{p}$ and $\left\{T_{j}\right\}_{j=1}^{r}$, i.e., there exists $\left\{\beta_{i}\right\}_{i=1}^{p} \subset(0,1)$ and $\left\{\mu_{j}\right\}_{j=1}^{r} \subset(0,1)$, such that

$$
\begin{aligned}
& \left\|U_{i} x-q\right\|^{2} \leq\|x-q\|^{2}+\beta_{i}\left\|x-U_{i} x\right\|^{2}, \quad x \in H, q \in F i x\left(U_{i}\right), i \in \triangle, \\
& \left\|T_{j} x-p\right\|^{2} \leq\|x-p\|^{2}+\mu_{j}\left\|x-T_{j} x\right\|^{2}, \quad x \in H, p \in F i x\left(T_{j}\right), j \in \nabla .
\end{aligned}
$$

Let $\beta=\max _{1 \leq i \leq p}\left\{\beta_{i}\right\}, \mu=\max _{1 \leq j \leq r}\left\{\mu_{j}\right\}$, then we have

$$
\begin{array}{ll}
\left\|U_{i} x-q\right\|^{2} \leq\|x-q\|^{2}+\beta\left\|x-U_{i} x\right\|^{2}, & \text { for all } x \in H, q \in F i x\left(U_{i}\right), i \in \triangle, \\
\left\|T_{j} x-p\right\|^{2} \leq\|x-p\|^{2}+\mu\left\|x-T_{j} x\right\|^{2}, & \text { for all } x \in H, p \in F i x\left(T_{j}\right), j \in \nabla .
\end{array}
$$

First, we prove the following lemma.

Lemma 4. Let $A: H_{1} \rightarrow H_{2}$ be a bounded linear operator, $\left\{U_{i}, i \in \triangle\right\}: H_{1} \rightarrow$ $H_{1}$ be $\beta_{i}$-demicontractive and $\left\{T_{j}, j \in \nabla\right\}: H_{2} \rightarrow H_{2}$ be $\mu_{j}$-demicontractive mappings. Assume the solution set $\Omega$ of (1.5) is nonempty, then the sequence $\left\{x_{n}\right\}$ generated by Algorithm 2 is the Féjer-monotone, i.e., for any $x \in \Omega$,

$$
\left\|x_{n+1}-x\right\| \leq\left\|x_{n}-x\right\|, \quad \forall n \geq 0,
$$

provided that $\gamma \in\left(0, \frac{1-\mu}{\lambda}\right]$ and $\alpha_{n} \in(0,1-\beta]$. 
Proof. Let $y \in \Omega$. By Lemma 2, we have

$$
\left\|x_{n+1}-y\right\|^{2} \leq\left\|u_{n}-y\right\|^{2}-\alpha_{n}\left(1-\beta-\alpha_{n}\right)\left\|U_{i(n)}\left(u_{n}\right)-u_{n}\right\|^{2} .
$$

Note that $u_{n}=x_{n}+\gamma A^{*}\left(T_{j(n)}-I\right) A x_{n}$, we get

$$
\begin{aligned}
\left\|u_{n}-y\right\|^{2}= & \left\|x_{n}+\gamma A^{*}\left(T_{j(n)}-I\right)\left(A x_{n}\right)-y\right\|^{2} \\
= & \left\|x_{n}-y\right\|^{2}+\gamma^{2}\left\|A^{*}\left(T_{j(n)}-I\right)\left(A x_{n}\right)\right\|^{2} \\
& +2 \gamma\left\langle x_{n}-y, A^{*}\left(T_{j(n)}-I\right)\left(A x_{n}\right)\right\rangle \\
= & \left\|x_{n}-y\right\|^{2}+\gamma^{2}\left\langle\left(T_{j(n)}-I\right)\left(A x_{n}\right), A A^{*}\left(T_{j(n)}-I\right)\left(A x_{n}\right)\right\rangle \\
& +2 \gamma\left\langle x_{n}-y, A^{*}\left(T_{j(n)}-I\right)\left(A x_{n}\right)\right\rangle \\
\leq & \left\|x_{n}-y\right\|^{2}+\lambda \gamma^{2}\left\|\left(T_{j(n)}-I\right)\left(A x_{n}\right)\right\|^{2} \\
& +2 \gamma\left\langle x_{n}-y, A^{*}\left(T_{j(n)}-I\right)\left(A x_{n}\right)\right\rangle .
\end{aligned}
$$

For the last term of the above inequality, using (ii) of Lemma 1, one has

$$
\begin{aligned}
2 \gamma & \left\langle x_{n}-y, A^{*}\left(T_{j(n)}-I\right)\left(A x_{n}\right)\right\rangle \\
& =2 \gamma\left\langle A\left(x_{n}-y\right),\left(T_{j(n)}-I\right)\left(A x_{n}\right)\right\rangle \\
& =2 \gamma\left\langle A\left(x_{n}-y\right)+\left(T_{j(n)}-I\right)\left(A x_{n}\right)-\left(T_{j(n)}-I\right)\left(A x_{n}\right),\left(T_{j(n)}-I\right)\left(A x_{n}\right)\right\rangle \\
& =2 \gamma\left(\left\langle T_{j(n)}\left(A x_{n}\right)-A y,\left(T_{j(n)}-I\right)\left(A x_{n}\right)\right\rangle-\left\|\left(T_{j(n)}-I\right)\left(A x_{n}\right)\right\|^{2}\right) \\
& \leq 2 \gamma\left(\frac{1+\mu}{2}\left\|\left(T_{j(n)}-I\right)\left(A x_{n}\right)\right\|^{2}-\left\|\left(T_{j(n)}-I\right)\left(A x_{n}\right)\right\|^{2}\right) \\
& =-\gamma(1-\mu)\left\|\left(T_{j(n)}-I\right)\left(A x_{n}\right)\right\|^{2} .
\end{aligned}
$$

Thus, by (3.1), (3.2) and (3.3), we obtain

$$
\begin{aligned}
\left\|x_{n+1}-y\right\|^{2} \leq & \left\|x_{n}-y\right\|^{2}-\alpha_{n}\left(1-\beta-\alpha_{n}\right)\left\|U_{i(n)}\left(u_{n}\right)-u_{n}\right\|^{2} \\
& -\gamma(1-\mu-\lambda \gamma)\left\|\left(T_{j(n)}-I\right)\left(A x_{n}\right)\right\|^{2} .
\end{aligned}
$$

Since $\alpha_{n} \in(0,1-\beta]$ and $\gamma \in\left(0, \frac{1-\mu}{\lambda}\right]$, then the sequence $\left\{x_{n}\right\}$ is Féjermonotone. This completes the proof.

Using this lemma, we obtain the following convergence result.

Theorem 2. Let $A: H_{1} \rightarrow H_{2}$ be a bounded linear operator, $\left\{U_{i}, i \in \triangle\right\}$ : $H_{1} \rightarrow H_{1}$ be $\beta_{i}$-demicontractive and $\left\{T_{j}, j \in \nabla\right\}: H_{2} \rightarrow H_{2}$ be $\mu_{j}$-demicontractive mapping. Assume that $\left\{I-U_{i}, i \in \triangle\right\}$ and $\left\{I-T_{j}, j \in \nabla\right\}$ are demiclosed at 0 and $\left\{U_{i}, i \in \triangle\right\},\left\{T_{j}, j \in \nabla\right\}$ are continuous. If the solution set $\Omega$ of (1.5) is nonempty, then the sequence $\left\{x_{n}\right\}$ generated by Algorithm 2 converges weakly to a solution of the $\Omega$, provided that $\gamma \in\left(0, \frac{1-\mu}{\lambda}\right)$ and $\alpha_{n} \in$ $(\delta, 1-\beta-\delta)$ for a small $\delta>0$.

Proof. From (3.4), and the fact that $\alpha_{n} \in(\delta, 1-\beta-\delta)$ and $\gamma \in\left(0, \frac{1-\mu}{\lambda}\right)$, we obtain

$$
\sum_{n=0}^{\infty}\left\|U_{i(n)}\left(u_{n}\right)-u_{n}\right\|^{2}<\infty, \quad \text { and } \quad \sum_{n=0}^{\infty}\left\|\left(T_{j(n)}-I\right)\left(A x_{n}\right)\right\|^{2}<\infty .
$$


Therefore,

$$
\lim _{n \rightarrow \infty}\left\|U_{i(n)}\left(u_{n}\right)-u_{n}\right\|=0
$$

and

$$
\lim _{n \rightarrow \infty}\left\|\left(T_{j(n)}-I\right)\left(A x_{n}\right)\right\|=0 .
$$

It follows from the Féjer-monotonicity of $\left\{x_{n}\right\}$ that the sequence is bounded. Let $x^{*} \in w_{\omega}\left(x_{n}\right)$. Take a subsequence $\left\{x_{n_{k}}\right\}$ of $\left\{x_{n}\right\}$ such that $x_{n_{k}} \rightarrow x^{*}$.

Since

$$
\begin{aligned}
\left\|x_{n+1}-x_{n}\right\|^{2} & =\left\|\left(1-\alpha_{n}\right)\left(x_{n}+\gamma A^{*}\left(T_{j(n)}-I\right)\left(A x_{n}\right)\right)+\alpha_{n} U_{i(n)}\left(u_{n}\right)-x_{n}\right\|^{2} \\
& =\left\|\gamma A^{*}\left(T_{j(n)}-I\right)\left(A x_{n}\right)+\alpha_{n}\left(U_{i(n)}\left(u_{n}\right)-u_{n}\right)\right\|^{2} \\
& \leq 2\left(\left\|\gamma A^{*}\left(T_{j(n)}-I\right)\left(A x_{n}\right)\right\|^{2}+\alpha_{n}^{2}\left\|U_{i(n)}\left(u_{n}\right)-u_{n}\right\|^{2}\right) .
\end{aligned}
$$

Thus,

$$
\sum_{n=0}^{\infty}\left\|x_{n+1}-x_{n}\right\|^{2}<\infty \text { and } \lim _{n \rightarrow \infty}\left\|x_{n+1}-x_{n}\right\|=0 .
$$

Notice $A$ is a bounded linear operator, then we have

$$
\left\|A x_{n+1}-A x_{n}\right\|^{2} \leq\|A\|^{2} \cdot\left\|x_{n+1}-x_{n}\right\|^{2} .
$$

Therefore, $\sum_{n=0}^{\infty}\left\|A x_{n+1}-A x_{n}\right\|^{2}<\infty$, it implies that $\lim _{n \rightarrow \infty} \| A x_{n+1}-$ $A x_{n} \|=0$. Hence

$$
\left\|A x_{n+j}-A x_{n}\right\| \rightarrow 0 \text { as } n \rightarrow \infty
$$

for all $j=1,2, \ldots, r$.

For each $j \in \nabla$, we get

$$
\begin{aligned}
\left\|A x_{n}-T_{[n+j]}\left(A x_{n}\right)\right\| \leq & \left\|A x_{n}-A x_{n+j}\right\|+\left\|A x_{n+j}-T_{[n+j]}\left(A x_{n+j}\right)\right\| \\
& +\left\|T_{[n+j]}\left(A x_{n+j}\right)-T_{[n+j]}\left(A x_{n}\right)\right\|,
\end{aligned}
$$

where $[n+j]:=(n+j)(\bmod r)+1$. Using the continuity of $\left\{T_{j}, j \in \nabla\right\},(3.6)$ and (3.7), we obtain

$$
\lim _{n \rightarrow \infty}\left\|A x_{n}-T_{[n+j]}\left(A x_{n}\right)\right\|=0 .
$$

It is clear that for each $l \in \nabla$, there exists $j \in \nabla$ such that $l=(n+j)(\bmod r)+1$. Consequently,

$$
\lim _{n \rightarrow \infty}\left\|A x_{n}-T_{l}\left(A x_{n}\right)\right\|=\lim _{n \rightarrow \infty}\left\|A x_{n}-T_{[n+j]}\left(A x_{n}\right)\right\|=0 .
$$

By the demiclosedness of $I-T_{l}$ at zero, $A x^{*} \in \bigcap_{j=1}^{r} F i x\left(T_{j}\right)$.

Now, by setting $u_{n}=x_{n}+\gamma A^{*}\left(T_{j(n)}-I\right) A x_{n}$, it follows that $x^{*} \in \omega_{w}\left(u_{n}\right)$. On the other hand,

$$
\begin{aligned}
\left\|u_{n+1}-u_{n}\right\|^{2}= & \| x_{n+1}-x_{n}+\gamma A^{*}\left(T_{j(n+1)}-I\right) A x_{n+1} \\
& -\gamma A^{*}\left(T_{j(n)}-I\right)\left(A x_{n}\right) \|^{2} \\
= & \left\|\alpha_{n}\left(U_{i(n)}\left(u_{n}\right)-u_{n}\right)+\gamma A^{*}\left(T_{j(n+1)}-I\right)\left(A x_{n+1}\right)\right\|^{2} \\
\leq & 2\left(\alpha_{n}^{2}\left\|U_{i(n)}\left(u_{n}\right)-u_{n}\right\|^{2}+\gamma^{2}\left\|A^{*}\left(T_{j(n+1)}-I\right)\left(A x_{n+1}\right)\right\|^{2}\right)
\end{aligned}
$$


that is, $\sum_{n=0}^{\infty}\left\|u_{n+1}-u_{n}\right\|^{2}<\infty$ and therefore $\lim _{n \rightarrow \infty}\left\|u_{n+1}-u_{n}\right\|=0$. Hence

$$
\left\|u_{n+i}-u_{n}\right\| \rightarrow 0 \text { as } n \rightarrow \infty
$$

for all $i \in \triangle$.

For each $i \in \triangle$, we get

$$
\begin{aligned}
\left\|u_{n}-U_{[n+i]}\left(u_{n}\right)\right\| \leq & \left\|u_{n}-u_{n+i}\right\|+\left\|u_{n+i}-U_{[n+i]}\left(u_{n+i}\right)\right\| \\
& +\left\|U_{[n+i]}\left(u_{n+i}\right)-U_{[n+i]}\left(u_{n}\right)\right\|,
\end{aligned}
$$

where $[n+i]:=(n+i)(\bmod p)+1$. By (3.5), (3.8) and together with the continuity of $\left\{U_{i}, i \in \triangle\right\}$, we have

$$
\lim _{n \rightarrow \infty}\left\|u_{n}-U_{[n+i]}\left(u_{n}\right)\right\|=0 .
$$

It is now clear that for each $k \in \triangle$, there exists $i \in \triangle$ such that $k=(n+$ $i)(\bmod p)+1$, then

$$
\lim _{n \rightarrow \infty}\left\|u_{n}-U_{k} u_{n}\right\|=\lim _{n \rightarrow \infty}\left\|u_{n}-U_{[n+i]}\left(u_{n}\right)\right\|=0 .
$$

Since $I-U_{k}$ is demiclosedness at zero and $x^{*} \in \omega_{w}\left(u_{n}\right)$, then $x^{*} \in \bigcap_{i=1}^{p} F i x\left(U_{i}\right)$.

By Lemma 3 , we conclude that the sequence $\left\{x_{n}\right\}$ converges weakly to a point in $\Omega$.

Remark 4. To conclude, we construct a cyclic algorithm for approximating the solution of the SCFP (1.5) which is a generalization of Moudafi[10].

\section{Acknowledgements}

The authors would like to thank the anonymous referees and editor for their helpful comments and suggestions which helped to improve this manuscript.

\section{References}

[1] H.H. Bauschke and J.M. Borwein. On projection algorithms for solving convex feasibility problems. SIAM Rev., 38:367-426, 1996. http://dx.doi.org/10.1137/S0036144593251710.

[2] H.H. Bauschke and P.L. Combettes. A weak-to-strong convergence principle for Fejér-monotone methods in Hilbert spaces. Math. Oper. Res., 26:248-264, 2001. http://dx.doi.org/10.1287/moor.26.2.248.10558.

[3] C. Byrne. Iterative oblique projection onto convex sets and the split feasibility problem. Inverse Problems, 18:441-453, 2002. http://dx.doi.org/10.1088/0266-5611/18/2/310.

[4] Y. Censor and T. Elfving. A multiprojection algorithm using bregman projections in a product space. Numer. Algorithms, 8:221-239, 1994. http://dx.doi.org/10.1007/BF02142692.

[5] Y. Censor, T. Elfving, N. Kopf and T. Bortfeld. The multiple-sets split feasibility problem and its applications for inverse problems. Inverse Problems, 21:20712084, 2005. http://dx.doi.org/10.1088/0266-5611/21/6/017. 
[6] Y. Censor, A. Motova and A. Segal. Perturbed projections and subgradient projections for the multiple-sets split feasibility problem. J. Math. Anal. Appl., 327:1244-1256, 2007. http://dx.doi.org/10.1016/j.jmaa.2006.05.010.

[7] Y. Censor and A. Segal. The split common fixed point problem for directed operators. J. Convex Anal., 16:587-600, 2009.

[8] H.M. He, S.Y. Liu and M.A. Noor. Some Krasnonselskii-Mann algorithms and the multiple-set split feasibility problem. Fixed Point Theory Appl., 2010, 2010. Article ID 513956, 12 pp.

[9] E. Masad and S. Reich. A note on the multiple-set split convex feasibility problem in Hilbert space. J. Nonlinear Convex Anal., 8(3):367-371, 2007.

[10] A. Moudafi. The split common fixed point problem for demicontractive mappings. Inverse Problems, 26:055007, 6 pp., 2010. http://dx.doi.org/10.1088/0266-5611/26/5/055007.

[11] B. Qu and N. Xiu. A note on the CQ algorithm for the split feasibility problem. Inverse Problems, 21:1655-1665, 2005. http://dx.doi.org/10.1088/0266-5611/21/5/009.

[12] B. Qu and N.H. Xiu. A new halfspace-relaxation projection method for the split feasibility problem. Linear Algebra Appl., 428:1218-1229, 2008. http://dx.doi.org/10.1016/j.laa.2007.03.002.

[13] Q.Yang and J.Zhao. Generalized KM theorems and their applications. Inverse Problems, 22:833-844, 2006. http://dx.doi.org/10.1088/0266-5611/22/3/006.

[14] F. Wang and H.K. Xu. Approximating curve and strong convergence of the CQ algorithm for the split feasibilityproblem. J. Inequal. Appl., 2010, 2010. Article ID 102085, 13 pp.

[15] F. Wang and H.K. Xu. Cyclic algorithms for split feasibility problems in Hilbert spaces. Nonlinear Anal., 74:4105-4111, 2011. http://dx.doi.org/10.1016/j.na.2011.03.044.

[16] H.K. Xu. A variable Krasnosel'skii-Mann algorithm and the multiple-set split feasibility problem. Inverse Problems, 22:2021-2034, 2006. http://dx.doi.org/10.1088/0266-5611/22/6/007.

[17] H.K. Xu. Iterative methods for the split feasibility problem in infinite dimensional Hilbert spaces. Inverse problems, 26:105018, 17 pp., 2010. http://dx.doi.org/10.1088/0266-5611/26/10/105018.

[18] Q. Yang. The relaxed CQ algorithm solving the split feasibility problem. Inverse Problems, 20:1261-1266, 2004. http://dx.doi.org/10.1088/0266-5611/20/4/014.

[19] H.Y. Zhang and Y.J. Wang. A new CQ method for solving split feasibility problem. Front. Math. China, 5(1):37-46, 2010. http://dx.doi.org/10.1007/s11464-009-0047-z.

[20] Z.W. Zhang, Q.Z. Yang and Y.N. Yang. The relaxed inexact projection methods for the split feasibility problem. Appl. Math. Comput., 217:5347-5359, 2011. http://dx.doi.org/10.1016/j.amc.2010.11.058.

[21] J. Zhao and Q. Yang. Several solution methods for the split feasibility problem. Inverse Problems, 21:1791-1799, 2005. http://dx.doi.org/10.1088/0266-5611/21/5/017. 